\title{
Clinicopathological findings in female-to-male gender-affirming breast surgery
}

\author{
Ellen G East, ${ }^{1}$ (D) Katherine M Gast, ${ }^{2}$ William M Kuzon Jr, ${ }^{2}$ Emily Roberts, ${ }^{3}$ Lili Zhao ${ }^{3}$ \& \\ Julie M Jorns ${ }^{1}$ (iD \\ ${ }^{1}$ Department of Pathology, ${ }^{2}$ Department of Surgery, Section of Plastic Surgery, Michigan Medicine, Ann Arbor, MI, \\ USA, and ${ }^{3}$ Department of Biostatistics, University of Michigan, Ann Arbor, MI, USA
}

Date of submission 23 March 2017

Accepted for publication 24 June 2017

Published online Article Accepted 28 June 2017

East E G, Gast K M, Kuzon Jr W M, Roberts E, Zhao L \& Jorns J M

(2017) Histopathology 71, 859-865. https://doi.org/10.1111/his.13299

\section{Clinicopathological findings in female-to-male gender-affirming breast surgery}

Aims: Gender dysphoria is a diagnosis whereby an individual identifies as the opposite gender. The management of patients seeking female-to-male (FTM) transition includes hormonal therapy and surgical intervention, including mastectomy. The aim of this study was to characterize the immunohistological findings in resection specimens from FTM patients.

Methods and results: We reviewed 68 cases (67 patients, one with re-excision) of FTM breast tissue resection by collecting clinical data, reviewing breast imaging and pathology reports (gross fibrous density, specimen weight, and number of cassettes submitted), and reviewing pathology slides [number of tissue pieces submitted, number of terminal duct lobule units (TDLUs), and the presence of histological findings]. Significant histological findings were present in 51 of $68(75.0 \%)$ cases, including one case $(1.5 \%)$ of flat epithelial atypia. Fibrocystic changes were the most common finding $(27 / 68,39.7 \%)$, followed by gynaecomastoid change, fibrotic stage, (22/68, $32.4 \%)$, and fibroadenomatoid change (11/68, 16.2\%). Fibrocystic change was associated with increased numbers of TDLUs, and gynaecomastoid change was associated with lower body mass index and decreased numbers of TDLUs. Gynaecomastoid change showed a moderate proportion of luminal epithelial cells with strong-intensity immunohistochemical staining for oestrogen receptor, progesterone receptor, and androgen receptor, and a three-layered epithelium demonstrated by the use of cytokeratin 5/6 immunohistochemistry.

Conclusions: We identified gynaecomastoid change at a significantly higher rate than previously reported in female patients. We support the continued gross and histological evaluation of FTM specimens in light of the identification of atypia in one case.

Keywords: breast, gender dysphoria, pathology, transgender

\section{Introduction}

Gender dysphoria is a diagnosis whereby an individual's gender identity differs from the external sexual anatomy at birth. ${ }^{1}$ The true incidence of gender dysphoria remains uncertain. Previous estimates of prevalence were based on indirect calculations of

Address for correspondence: J M Jorns, Department of Pathology, Michigan Medicine, 1500 E. Medical Center Dr., Rm 2G332, Ann Arbor, MI 48109, USA. e-mail: jjorns@med.umich.edu those who apply for gender reassignment, receive a diagnosis of gender dysphoria, start gender-affirmation treatment, and/or apply for legal gender recognition. $^{2-10}$ Recent population-based survey methods have shown that $0.6 \%$ of adults ( 1.4 million individuals) and $0.7 \%$ of youths aged $13-17$ years (150 000 individuals) in the USA identify as transgender. ${ }^{11,12}$ The management of patients seeking female-to-male (FTM) transition includes hormonal therapy and surgical intervention. ${ }^{13,14}$ As patients are increasingly seeking gender-affirming surgery, 
Michigan Medicine has become a destination centre for patients seeking surgical intervention for gender dysphoria. $^{2}$

Currently, there are limited data in the published literature on the histological findings in resection specimens from FTM gender-affirming surgeries. The most commonly reported changes are fibrosis, atrophy, and fibrocystic changes. ${ }^{15}$ Here, we aim to provide a comprehensive review of the clinical characteristics, gross findings and immunohistological features of FTM breast specimens.

\section{Materials and methods}

CASE SELECTION

Following institutional review board approval, all cases of FTM transgender affirmation with resection of breast tissue (1998-2016) were retrieved from Michigan Medicine Department of Pathology archives.

CLINICAL AND PATHOLOGICAL DATA

Clinical data, including patient age, body mass index (BMI), the presence and duration of hormone therapy, smoking history, parity, breast imaging findings, and family history, were retrieved from medical records. Specimens had previously undergone gross and histological evaluation via standard protocols. All patient pathology reports and slides were available for review. Pathology reports were reviewed for weight, gross fibrous density (percentage fibrous tissue), the presence of gross lesions, the number of tissue pieces submitted for microscopic examination, and the number of cassettes submitted per case. All haematoxylin and eosin slides were reviewed by two pathologists (E.G.E. and J.M.J.) for the number of terminal duct lobular units (TDLUs) per case and the presence of histological findings. TDLUs were scored as absent if none were present, rare if one to three were present, and frequent if more than three were present.

\section{M M U N O H I S T O C HE M I S TR Y}

Immunohistochemical (IHC) staining was performed on 22 cases with gynaecomastoid change. Commercially available antibodies used were: anti-oestrogen receptor (ER) (clone SP1, 1:50 dilution; Cell Marque, Rocklin, CA, USA), anti-progesterone receptor (PR) (clone Y85, 1:40 dilution; Cell Marque), and anti-androgen receptor (AR) (clone AR441, 1:100 dilution; Thermo-Scientific, Fremont, CA, USA). IHC staining for cytokeratin (CK) $5 / 6$ was performed on selected cases (clone D5/16B4; Ventana Medical Systems, Tucson, AZ, USA). Staining was performed on the Dako Autostainer platform (Agilent Technologies, Santa Clara, CA, USA), according to the manufacturer's instructions, with appropriate controls.

Oestrogen receptor, PR and AR staining in gynaecomastoid change was scored by a breast pathologist (J.M.J.), and reported via the Allred scoring system, with intensity scores (negative, 0; weak, 1; intermediate, 2; strong, 3) and proportion scores (none positive, $0 ; \leq 1 \%, 1 ; 1-10 \%, 2 ; 11-33 \%, 3$; $34-66 \%, 4 ; 67-100 \%, 5)$ being added to generate a sum score (with scores of 0-2 being interpreted as negative and 3-8 as positive. Background uninvolved (non-gynaecomastoid) glands served as internal controls.

ST A TISTICAL ANALYSIS

Descriptive statistics are presented, including continuous data (mean and range) and categorical data (frequency and percentage). A simple logistic regression model was used to associate clinical, gross and histopathological findings with gynaecomastoid change. A multivariate logistic regression model was generated for the outcome of gynaecomastoid change, with variables for age, BMI, smoking status, number of TDLUs, mean gross fibrous density, total specimen weight, and the use and duration of androgen therapy. Two-way interactions for TDLUs and mean gross fibrous density, mean gross fibrous density and androgen use, and mean gross fibrous density and BMI were included. A stepwise variable selection procedure was used to select important variables to be included in final logistic regression model (a significance level of 0.35 was used to allow a variable into the model, and a significance level of 0.20 was used for a variable to stay in the model). The final model included BMI and TDLU (0-3). A P-value of $\leq 0.05$ was considered to be statistically significant. All analyses were conducted with SAS (version 9.4; SAS Institute, Cary, NC, USA).

\section{Results}

P A T IENTS

A total of 68 cases (67 patients with simple mastectomy and free nipple grafting; one with re-excision) of FTM with breast tissue resection were identified. 
The mean age at the time of surgery was 31.5 years (range 19-57 years). Most patients (60/67, 89.6\%) had undergone androgen therapy prior to surgery. Two patients had undergone pregnancy and childbirth prior to FTM transition. Family history was available for $66(98.5 \%)$ patients, and was significant for breast cancer in a single relative in 13 $(19.7 \%)$ patients and for ovarian cancer in a single relative in one $(1.5 \%)$ patient. Breast imaging prior to surgery was infrequent $(8 / 67 ; 11.9 \%)$ (Table 1 ) and benign for all patients; for six $(75 \%)$, the indication was for routine screening, and for one $(12.5 \%)$ there was a palpable lesion for which biopsy resulted in the diagnosis of fibroadenoma $(1 ; 12.5 \%$ unknown).

\section{GROSS FINDINGS}

Specimen weight was recorded in the majority of cases, and the mean total weight was $1100.2 \mathrm{~g}$. The mean gross fibrous density was $26.3 \%$. A median of six (range 2-20) tissue pieces were submitted in a median of two (range 2-16) cassettes per case. Gross lesions were infrequently identified $(13 / 68 ; 19.1 \%)$ (Table 1).

\section{H IS T OL O G I C A L FIN DING S}

Terminal duct lobule units were absent in $11.8 \%$ $(8 / 68)$ of cases, rare in $27.9 \%(19 / 68)$, and frequent in $60.3 \%(41 / 68)$. Diagnostic findings were present in $75 \%(51 / 68)$ of cases. Fibrocystic changes (27/68; $39.7 \%$ ) were most frequent (Table 1; Figure 1). Univariate analysis showed fibrocystic changes to be significantly associated with the presence of frequent TDLUs $(P=0.0055)$.

Gynaecomatoid change was present in 22 (32.4\%) patients, with all cases having features characteristic of those seen in the fibrotic stage of gynaecomastia of the male breast, including atrophic duct epithelium and periductal hyalinization and fibrosis (Figures 1 and 2). Univariate analysis showed gynaecomastoid change to be significantly associated with younger age $(P=0.0402)$, lower BMI $(P=0.0169)$, increased gross fibrous density $(P=0.0087)$, increased total specimen weight $(P=0.0376)$, and absent or rare TDLUs $(P=0.0003)$. Multivariate analysis showed gynaecomastoid change to be significantly associated with absent or rare TDLUs $(P=0.0016)$ and lower BMI $(P=0.0087)$ (Table 2).

No specific histological feature was significantly associated with gross findings or sampling of greater numbers of tissue pieces or cassettes.

\section{M M U N O H I S T O C HEM I S T R Y}

Immunohistochemistry staining performed on 22 cases of gynaecomastoid change showed a moderate proportion of strong-intensity glandular staining for ER, PR, and AR. Specifically, for ER the median Allred score was 6 , with range of $5-7$, for PR the median Allred score was 6 , with range of $4-7$, and for AR the median Allred score was 6 , with range of 4-7. The mean AR/ER Allred score ratio was 0.9 (range 0.7-1.0) (Figure 2A-D). CK5/6 IHC staining performed on eight blocks with gynaecomastoid change showed positive staining in the outer myoepithelial and inner ductal epithelial layers, with no staining in a discontinuous intermediate epithelial layer (Figure 2E,F).

\section{Discussion}

Here, we present a comprehensive immunomorphological study of FTM breast resection specimens and identify features unique to these uncommon specimens. These specimens provide insights into androgen-stimulated breast tissue in a unique patient population.

Benign breast disease, particularly fibrocystic change, is a common finding, being identified in up to $58.5 \%$ of asymptomatic women. ${ }^{16,17}$ In this study, we identified fibrocystic change in $39.7 \%$ of FTM specimens, which is similar to the proportion noted by Kuroda et al. ${ }^{18}(60 / 186 ; 32.3 \%)$. In postmenopausal women receiving oestrogens for $\geq 8$ years, the prevalence of fibrocystic change is increased 1.7-fold, supporting a role for increased oestrogenic states contributing to the development of fibrocystic change. ${ }^{19}$ As increased BMI is associated with an increased oestrogenic state, and TDLU development is partially driven by the influence of oestrogen, the association of fibrocystic change in FTM patients with increased BMI and increased numbers of TDLUs is anticipated. ${ }^{16,20-22}$

Gynaecomastia-like hyperplasia has been described as a proliferative lesion of the female breast with histological features typical of gynaecomastia of the male breast. ${ }^{23,24}$ However, unlike fibrocystic disease, the frequent finding of gynaecomastoid change in $32.4 \%$ of FTM patients is unusual, considering its otherwise rare existence in female patients, with previously reported incidence rates of $0.15 \%$ and $0.56 \%{ }^{24,25}$ In our study, all cases with gynaecomastoid change had findings identical to those seen in the fibrotic stage of male gynaecomastia. Previous 
Table 1. Clinicopathological features of female-to-male transgender-affirming patients who underwent resection of breast tissue ( $n=68$ unless otherwise stated)

\begin{tabular}{lc}
\hline Characteristics & \multicolumn{1}{l}{ Value } \\
\hline Clinical characteristics & $31.5(19-57)$ \\
\hline Age (years), mean (range) & $31.7(19.2-59.0)$ \\
\hline BMI, mean (range), $n=66$ & $5(7.6)$ \\
\hline Positive smoking status, $n(\%), n=66$ & $60(89.6)$ \\
\hline Androgen therapy, $n(\%), n=67$ & $1.89(0.2-10.0)$ \\
\hline $\begin{array}{l}\text { Duration (years), mean (range) } \\
\text { Prior pregnancy resulting in live birth, }\end{array}$ & $8(11.9)$ \\
\hline $\begin{array}{l}\text { Prior breast imaging performed, } n(\%), \\
n=67\end{array}$ & $14(21.2)$ \\
\hline $\begin{array}{l}\text { Family history of breast or ovarian } \\
\text { cancer, } n \text { (\%), } n=66\end{array}$ & $13(19.7)$ \\
\hline $\begin{array}{l}\text { Non-first degree relative* } \\
\text { First-degree relative } \dagger\end{array}$ & $1(1.5)$ \\
\hline \begin{tabular}{l} 
Gross characteristics \\
\hline
\end{tabular}
\end{tabular}

\begin{tabular}{lc}
\hline Total weight (g), mean (range), $n=61$ & $1100.2(46.5-2890.0)$ \\
\hline Fibrous density, mean (range), $n=53$ & $26.3(3-77.5)$ \\
\hline Cassettes submitted, median (range) & $2(2-16)$ \\
\hline $\begin{array}{l}\text { Total pieces submitted, median } \\
\text { (range), } n=67\end{array}$ & $6(2-20)$ \\
\hline Number of TDLUs, $n(\%)$ & $8(11.8)$ \\
\hline Absent (0) & $19(27.9)$ \\
\hline Rare (1-3) & $41(60.3)$ \\
\hline Frequent (>3) & $13(19.1)$ \\
\hline Gross lesion identified, any type, $n(\%)$ & $8(11.8)$ \\
\hline Cysts & $3(4.4)$ \\
\hline Nodularity & $2(2.9)$ \\
\hline Discolouration
\end{tabular}

Histological characteristics, $n(\%)$

\begin{tabular}{ll}
\hline Diagnostic finding, any type & $51(75.0)$ \\
\hline Fibrocystic changes & $27(39.7)$ \\
\hline Simple cysts & $22(32.4)$ \\
\hline Apocrine metaplasia & $16(23.5)$ \\
\hline Adenosis & $5(7.4)$ \\
\hline Usual ductal hyperplasia & $3(4.4)$ \\
\hline
\end{tabular}

Table 1. (Continued)

\begin{tabular}{lc}
\hline Characteristics & \multicolumn{1}{l}{ Value } \\
\hline $\begin{array}{l}\text { Gynaecomastoid change, } \\
\text { fibrotic stage }\end{array}$ & $22(32.4)$ \\
\hline Fibroadenomatoid change & $11(16.2)$ \\
\hline Duct ectasia & $12(17.6)$ \\
\hline Lactational changes & $2(2.9)$ \\
\hline Intraductal papilloma & $1(1.5)$ \\
\hline Flat epithelial atypia & $1(1.5)$ \\
\hline
\end{tabular}

BMI, Body mass index; TDLU, Terminal duct lobular unit.

* Breast cancer $(n=12)$, ovarian cancer $(n=1)$.

$\dagger$ Breast cancer in mother (postmenopausal).

studies of FTM breast tissue resection have primarily noted fibrocystic changes as well as fibrosis and involutionary changes or lobular atrophy. ${ }^{15,18,26,27}$ The fibrotic-stage gynaecomastoid change seen in our study may be associated with and/or represent an end-stage histological finding as part of the spectrum of fibrosis and atrophy described previously.

The majority of FTM patients, including all 22 with gynaecomastoid change, had undergone some duration of androgen therapy. We did not find a statistically significant correlation between gynaecomastoid change and androgen therapy use or duration. However, we found gynaecomastoid change to be significantly associated with lower BMI, which is probably explained by increased exogenous androgen and reduced endogenous oestrogen levels, as crosssex hormone therapy is known to increase total body weight and lean body mass in FTM patients. ${ }^{28}$ In this study, it was difficult to assess overall cumulative doses of exogenous androgens, as some patients had received these therapies elsewhere, had intermittent use because of lack of insurance coverage, and had variable documentation of dosing in the available clinical notes. This is a notable limitation of this study, as the degree of androgen exposure is probably a key factor, in addition to BMI, resulting in gynaecomastoid change in FTM breast tissue.

In light of the increased prevalence of gynaecomastoid change in FTM patients, we sought to compare the IHC profile with that of male gynaecomastia. Previous reports have shown that gynaecomastic breast tissue in male patients expresses receptors for oestradiol, progesterone, and androgens, ${ }^{29-32}$ and has a characteristic three-layered ductal epithelium with an outer myoepithelial and two inner epithelial layers. ${ }^{33}$ 

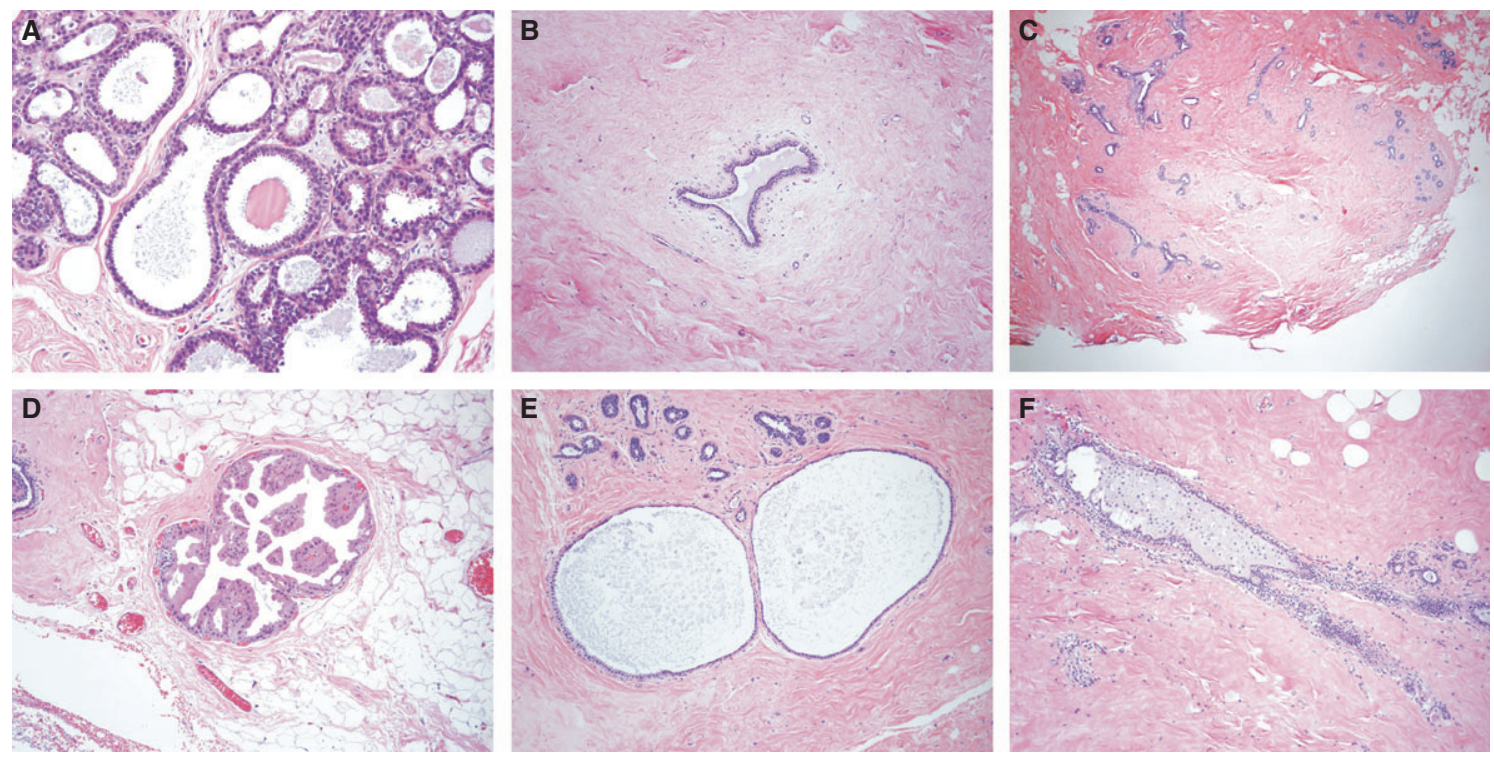

Figure 1. Histological findings in female-to-male breast resection specimens. A, Flat epithelial atypia. B, Gynaecomastoid change. C, Fibroadenomatoid change. D, Apocrine metaplasia. E, Simple cysts. F, Duct ectasia.

Figure 2. A-D,

Gynaecomastoid change (A), with oestrogen receptor (B) (proportion 3, intensity 3), progesterone receptor $(\mathbf{C})$ (proportion 2, intensity 3) and androgen receptor (D) (proportion 3, intensity 3) immunohistochemical staining. E,F, Gynaecomastoid change (E), with cytokeratin $5 / 6$ immunohistochemistry highlighting the outer myoepithelial and inner ductal epithelial layers, with no staining in the intermediate epithelial layer (F).
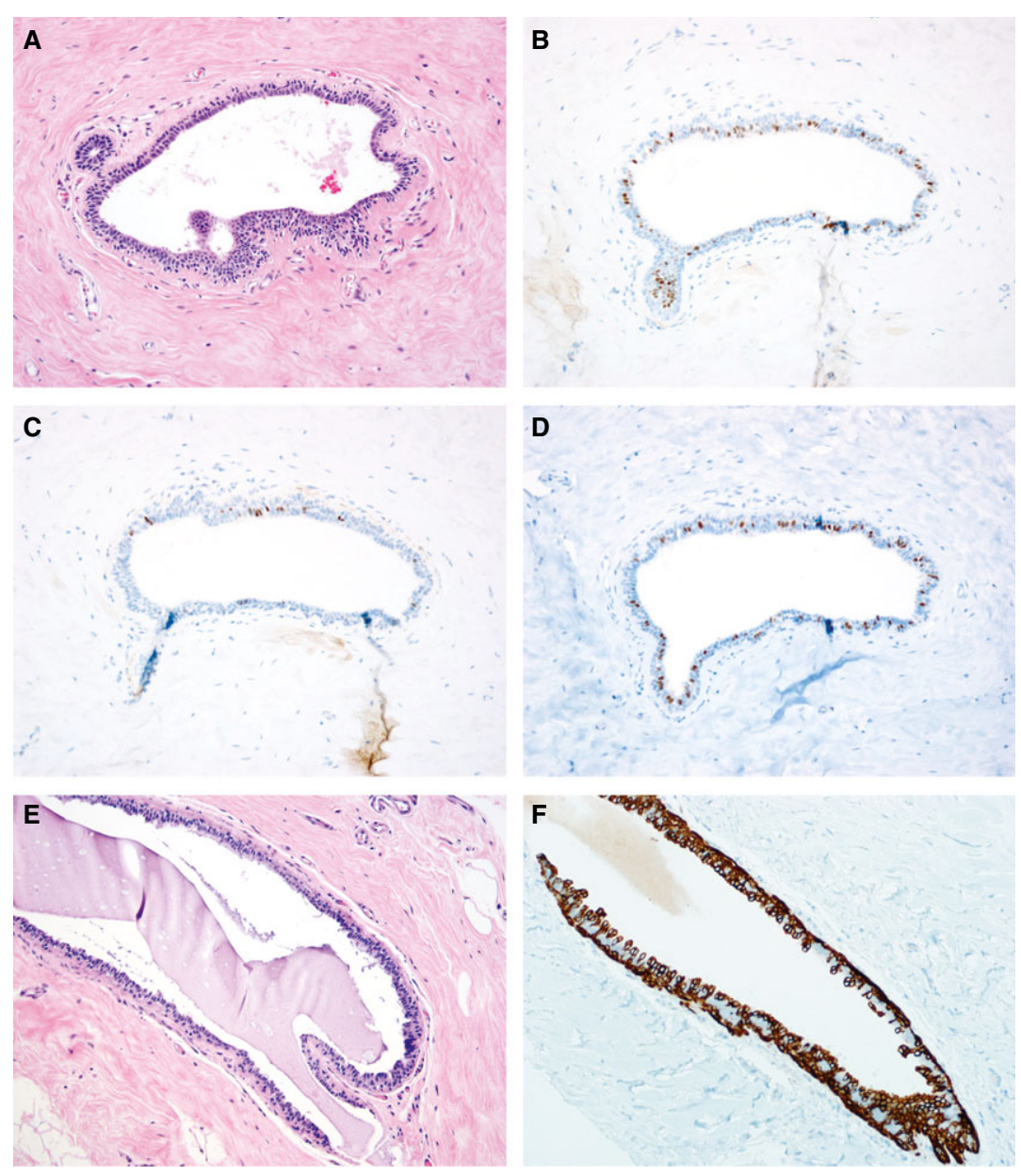
Table 2. Features associated with gynaecomastoid change: univariate and multivariate analysis

\begin{tabular}{lll}
\hline Clinicopathological feature & Odds ratio $(95 \% \mathrm{Cl})$ & $P$-value \\
\hline Univariate analysis & & \\
\hline BMI & $0.901(0.828-0.981)$ & 0.0169 \\
\hline Age & $0.931(0.869-0.997)$ & 0.0402 \\
\hline Gross fibrous density & $1.044(1.011-1.078)$ & 0.0087 \\
\hline Total specimen weight & $0.999(0.998-1.000)$ & 0.0376 \\
\hline Absent-rare TDLUs & $8.484(2.667-26.990)$ & 0.0003 \\
\hline Multivariate analysis, $n=48$ & & \\
\hline BMI & $0.826(0.717-0.953)$ & 0.0087 \\
\hline Absent-rare TDLUs & $21.347(3.187-142.981)$ & 0.0016 \\
\hline
\end{tabular}

$\mathrm{BMI}$, Body mass index; $\mathrm{Cl}$, Confidence interval; TDLU, Terminal duct lobular unit.

Benign luminal cells of the breast have been shown to have scattered, strong positivity for AR in a pattern similar to that for ER, with the majority of those cells showing dual staining for ER and AR. ${ }^{34}$ In our study, gynaecomastoid change showed consistent positivity for ER and AR in a moderate proportion of cells with strong intensity of staining, consistent with that reported previously. Additionally, we noted the previously reported three-layered staining pattern via CK 5/6 IHC staining in selected cases with gynaecomastoid change. Overall, the IHC patterns seen in gynaecomastoid change in FTM patients parallel those reported in male gynaecomastic tissue.

Our findings support the continued gross and microscopic evaluation of these unique FTM breast resection specimens, particularly in light of the presence of atypia in one case $(1.5 \%)$. This is similar to the study by Kuroda et al., ${ }^{18}$ who noted atypia in three $(1.6 \%)$ and in-situ carcinoma in one $(0.5 \%)$ of 186 Japanese FTM patients undergoing resection of breast tissue. Similarly, resection of clinically benign reduction mammoplasty specimens identified atypia or carcinoma in $0.16-2.1 \% .^{35,36}$ Ambaye et al. prospectively evaluated the submission of additional cassettes of suspicious or fibrous tissue from reduction mammoplasty specimens, and found improved detection of atypia and carcinoma in patients aged $>40$ years. ${ }^{37}$ Although the number of cassettes and number of tissue pieces in our study were not associated with a particular histological finding, we recommend targeted sampling in multiple areas of gross fibrous density, as would be performed in other benign breast specimens.
As noted above, the main limitation of this study is a lack of data on cumulative androgen exposure. Additionally, larger future studies would be helpful as these surgeries become more frequently performed. Specifically, more data are needed to determine "best practices' for gross sampling of these specimens, and to determine features that may aid in identifying patients at risk for atypical or malignant pathology.

In summary, we have identified unique histological findings associated with FTM breast resection specimens. Specifically, the relatively frequent finding of gynaecomastoid change appears to be related to therapeutic alteration of the ratio of (exogenous) androgen and (endogenous) oestrogen in many FTM patients. Our findings support the continued gross and histological evaluation of these uncommon specimens,

\section{Acknowledgements}

No external funding was used for this study. The cost of immunohistochemistry was funded internally by the Michigan Medicine Department of Pathology Anatomic Pathology Projects Fund. This manuscript was presented in part at the United States and Canadian Academy of Pathology (USCAP) annual meeting, 6 March 2017, San Antonio, TX.

\section{Conflicts of interest}

The authors have no conflicts of interest.

\section{Author contributions}

K. M. Gast and W. M. Kuzon, Jr collected cases for the study and edited the manuscript. E. G. East and J. M. Jorns designed the research study, performed the research, and wrote the manuscript. E. Roberts and L. Zhao analysed the data, and contributed to writing and editing of the manuscript.

\section{References}

1. American Psychiatric Association, American Psychiatric Association, DSM-5 Task Force. Diagnostic and statistical manual of mental disorders: Dsm-5. 5th edn. Arlington, VA: American Psychiatric Association, 2013; xliv.

2. Dhejne C, Oberg K, Arver S, Landen M. An analysis of all applications for sex reassignment surgery in Sweden, 19602010: Prevalence, incidence, and regrets. Arch. Sex. Behav. 2014; 43; 1535-1545.

3. Gomez-Gil E, Trilla A, Salamero M, Godas T, Valdes M. Sociodemographic, clinical, and psychiatric characteristics of transsexuals from Spain. Arch. Sex. Behav. 2009; 38; 378-392. 
4. Hoenig J, Kenna JC. The prevalence of transsexualism in England and Wales. Br. J. Psychiatry 1974; 124; 181-190.

5. Landen M, Walinder J, Lundstrom B. Prevalence, incidence and sex ratio of transsexualism. Acta Psychiatr. Scand. 1996; 93; 221223.

6. Olsson SE, Moller AR. On the incidence and sex ratio of transsexualism in Sweden, 1972-2002. Arch. Sex. Behav. 2003; 32; 381-386.

7. Ross MW, Walinder J, Lundstrom B, Thuwe I. Cross-cultural approaches to transsexualism. A comparison between Sweden and Australia. Acta Psychiatr. Scand. 1981; 63; 75-82.

8. Sorensen T, Hertoft P. Male and female transsexualism: the Danish experience with 37 patients. Arch. Sex. Behav. 1982; $11 ; 133-155$.

9. Walinder J. Incidence and sex ratio of transsexualism in Sweden. Br. J. Psychiatry 1971; 119; 195-196.

10. Weitze C, Osburg S. Transsexualism in Germany: empirical data on epidemiology and application of the German Transsexuals' Act during its first ten years. Arch. Sex. Behav. 1996; 25; 409-425.

11. Flores AR, Herman JL, Gates GJ, Brown TNT. How many adults identify as transgender in the United States? The Williams Institute, 2016. https://williamsinstitute.law.ucla.edu/wp-content/ uploads/How-Many-Adults-Identify-as-Transgender-in-the-Uni ted-States.pdf

12. Herman JL, Flores AR, Brown TNT, Wilson BDM, Conron KJ. Age of individuals who identify as transgender in the United States. The Williams Institute, 2017. https://williamsinstitute.law.uc la.edu/wp-content/uploads/TransAgeReport.pdf

13. Monstrey S, Hoebeke P, Dhont M et al. Surgical therapy in transsexual patients: a multi-disciplinary approach. Acta Chir. Belg. 2001; 101; 200-209.

14. World Professional Association for Transgender Health. Standards of care for the health of transsexual, transgender, and gender nonconforming people. Version 7, 2012. https://www. Wpath.Org/site_page.Cfm?Pk_association_webpage_menu= 1351\&pk_association_webpage $=3926$

15. Grynberg M, Fanchin R, Dubost G et al. Histology of genital tract and breast tissue after long-term testosterone administration in a female-to-male transsexual population. Reprod. Biomed. Online 2010; 20; 553-558.

16. Goehring C, Morabia A. Epidemiology of benign breast disease, with special attention to histologic types. Epidemiol. Rev. 1997; 19; 310-327.

17. Davis HH, Simons M, Davis JB. Cystic disease of the breast: relationship to carcinoma. Cancer 1964; 17; 957-978.

18. Kuroda H, Ohnisi K, Sakamoto G, Itoyama S. Clinicopathological study of breast tissue in female-to-male transsexuals. Surg. Today 2008; 38; 1067-1071.

19. Rohan TE, Negassa A, Chlebowski RT et al. Estrogen plus progestin and risk of benign proliferative breast disease. Cancer Epidemiol. Biomarkers Prev. 2008; 17; 2337-2343.

20. McDivitt RW, Stevens JA, Lee NC, Wingo PA, Rubin GL, Gersell D. Histologic types of benign breast disease and the risk for breast cancer. The Cancer and Steroid Hormone Study Group. Cancer 1992; 69; 1408-1414.

21. London SJ, Connolly JL, Schnitt SJ, Colditz GA. A prospective study of benign breast disease and the risk of breast cancer. JAMA 1992; 267; 941-944.
22. Santen RJ. Benign breast disease in women. In De Groot LJ, Chrousos G, Dungan K, Feingold KR, Grossman A, Hershman JM, Koch C, Korbonits M, McLachlan R, New M, Purnell J, Rebar R, Singer F, Vinik A eds. Endotext. South Dartmouth, MA: MDText.com, Inc., 2000.

23. Rosen PP. Rosen's breast pathology. Philadelphia, PA: Lippincott Williams \& Wilkins, 2008.

24. Umlas J. Gynecomastia-like lesions in the female breast. Arch. Pathol. Lab. Med. 2000; 124; 844-847.

25. Kang Y, Wile M, Schinella R. Gynecomastia-like changes of the female breast. Arch. Pathol. Lab. Med. 2001; 125; 506509.

26. Burgess HE, Shousha S. An immunohistochemical study of the long-term effects of androgen administration on female-to-male transsexual breast: a comparison with normal female breast and male breast showing gynaecomastia. J. Pathol. 1992; 170; 37-43.

27. Slagter MH, Gooren LJG, Scorilas A, Petraki CD, Diamandis EP. Effects of long-term androgen administration on breast tissue of female-to-male transsexuals. J. Histochem. Cytochem. 2006; 54; 905-910.

28. Klaver M, Dekker MJ, de Mutsert R, Twisk JW, den Heijer M. Cross-sex hormone therapy in transgender persons affects total body weight, body fat and lean body mass: a meta-analysis. Andrologia 2016; 49; e12660.

29. Grilli S, De Giovanni C, Galli MC et al. The simultaneous occurrence of cytoplasmic receptors for various steroid hormones in male breast carcinoma and gynaecomastia. J. Steroid Biochem. 1980; 13; 813-820.

30. Pacheco MM, Oshima CF, Lopes MP, Widman A, Franco EL, Brentani MM. Steroid hormone receptors in male breast diseases. Anticancer Res. 1986; 6; 1013-1017.

31. Rosen PP, Menendez-Botet CJ, Nisselbaum JS, Schwartz MK, Urban JA. Estrogen receptor protein in lesions of the male breast: a preliminary report. Cancer 1976; 37; 18661868.

32. Kraus TS, Cohen C, Siddiqui MT. Prostate-specific antigen and hormone receptor expression in male and female breast carcinoma. Diagn. Pathol. 2010; 5; 63.

33. Kornegoor R, Vershuur-Maes AHJ, Buerger H, Van Diest PJ. The 3-layered ductal epithelium in gynecomastia. Am. J. Surg. Pathol. 2012; 36; 762-768.

34. Wang X, Yarid N, McMahon L, Yang Q, Hicks DG. Expression of androgen receptor and its association with estrogen receptor and androgen receptor downstream proteins in normal/benign breast luminal epithelium. Appl. Immunohistochem. Mol. Morphol. 2014; 22; 498-504.

35. Ishag MT, Bashinsky DY, Beliaeva IV, Niemann TH, Marsh WL Jr. Pathologic findings in reduction mammaplasty specimens. Am. J. Clin. Pathol. 2003; 120; 377-380.

36. Jansen DA, Murphy M, Kind GM, Sands K. Breast cancer in reduction mammoplasty: case reports and a survey of plastic surgeons. Plast. Reconstr. Surg. 1998; 101; 361-364.

37. Ambaye AB, MacLennan SE, Goodwin AJ, Suppan T, Naud S, Weaver DL. Carcinoma and atypical hyperplasia in reduction mammaplasty: increased sampling leads to increased detection. A prospective study. Plast. Reconstr. Surg. 2009; 124; 13861392. 